\title{
Update on Central Precocious Puberty: From Etiologies to Outcomes
}

Sena Cantas-Orsdemir \& Erica A. Eugster

\begin{abstract}
$\underline{\text { Abstract }}$
Introduction:

Precocious puberty (PP) is one of the most common reasons for referral to pediatric endocrinologists worldwide. Gonadotropin-releasing hormone analogs (GnRHas) are the gold standard for the treatment of central precocious puberty (CPP) and have an impressive track record of safety and efficacy. However, ongoing refinements in diagnosis and management continue to lead to important advancements in clinical care.

Areas Covered: The aim of this review is to cover current considerations and controversies regarding the diagnosis of CPP, as well as new findings in regards to etiology and treatment modalities.
\end{abstract}

Expert Commentary: There is emerging evidence of monogenic etiologies of CPP and significant progress in the expansion of newer formulations of GnRHas. Despite these exciting developments, areas of uncertainty in the diagnosis and treatment of CPP remain. While long-term outcomes of patients treated for CPP are encouraging, only short-term follow-up is available with respect to the newer extended-release GnRHa preparations, and how they compare with historically used formulations is unknown. A particular shortage of information exists pertaining to CPP in boys and regarding the psychological implications of early puberty in girls, and more research is needed. Continued investigation will yield new insights into the underlying genetics and optimal treatment strategies for CPP.

\section{Introduction}

This is the author's manuscript of the article published in final edited form as: 
Precocious puberty (PP) has been historically defined as the development of secondary sexual characteristics before the age of 9 years in boys, $7 \frac{1}{2}$ years in African American and Hispanic girls and 8 years in Caucasian girls [1]. During the last several decades, this classic definition has been challenged by accumulating data suggesting a trend of an earlier onset of puberty, particularly in girls, and revised guidelines recommending a lower age threshold for PP have been advocated. However, due to concerns about missing pathology as well as the observation that the average age of menarche has not changed, the general consensus is that the traditional age cut-offs for PP remain appropriate in the clinical setting [2].

The three major categories of PP are central PP, peripheral PP and benign variants. Central precocious puberty (CPP) is caused by early maturation of the hypothalamic-pituitary-gonadal (HPG) axis, and will be the sole focus of this review. Although the onset is earlier, the pattern and timing of pubertal events are the same as in normally timed puberty. The initial clinical sign of CPP in girls is breast development. The growth spurt usually occurs during breast Tanner stage 2-3, followed by the first menstrual period which typically occurs at Tanner stage 4 . The initial clinical sign of CPP in boys is testicular enlargement. The growth spurt happens later as compared to girls [3, 4]. Both boys and girls with CPP have accelerated linear growth for age, an advanced bone age, and pubertal levels of luteinizing hormone (LH) and follicle-stimulating hormone (FSH).

The initiation of puberty is a complex process with multiple levels of regulation. Although the exact mechanism is still unknown, the first biochemical event that initiates HPG axis activation is a rise in kisspeptin [3]. This is followed by activation of the GnRH pulse generator resulting in an increase in LH pulse amplitude initially at night and subsequently also during the day. This in turn is followed by a rise in estrogen and testosterone production from the gonads. 
CPP can be idiopathic, due to genetic mutations or associated with central nervous system (CNS) abnormalities or insults. Regardless of the cause, safe and effective treatment exists in the form of gonadotropin-releasing hormone analogs (GnRHas) with the major goal of intervention being the prevention of short final adult height. In this review, we will provide an update of the etiologies of CPP along with diagnostic and treatment considerations, therapeutic options and long-term outcomes.

\section{Etiology:}

CPP is far more common in girls than in boys [5, 6]. It is idiopathic in 80 to 90 percent of cases in girls, whereas intracranial lesions are detected in more than half of cases involving boys [1,7]. Risk factors for CPP include congenital or acquired CNS disorders as well as international adoption. Several genetic syndromes are also associated with CPP [3]. Secondary CPP can occur in patients who initially present with peripheral PP, particularly when the bone age is significantly advanced. Familial cases have been reported as well [8,9]. Table 1 summaries etiologies and known risk factors for CPP.

There has been exciting emerging evidence from several ongoing investigations of genetic causes of CPP during the past decade. These include rare genetic mutations in the gene encoding for kisspeptin (KISS1) and its receptor (KISS1R) which were found in patients with CPP resulting in an increased amplitude of GnRH pulsatility and/or prolonged intracellular signaling [10-12]. However, the most common mutation found in both sporadic and familial CPP thus far is in the imprinted gene $M K R N 3$ which encodes for makorin ring finger 3 [13-15]. Animal studies have demonstrated that a decline in mkrn3 expression is correlated with a rise in kiss 1 expression, leading to the supposition that down-regulation of $M K R N 3$ is permissive for $\mathrm{GnRH}$ pulses during puberty [15]. Therefore, deficiency of MKRN3 would be expected to result in a loss of inhibition 
of HPG axis activation. A second imprinted gene, $D L K 1$, has also been implicated in kindreds with CPP in which expression is limited to individuals inheriting the paternal allele [16]. Single nucleotide polymorphisms (SNPs) in the FSHB gene and the $L H B$ gene [17] and mutations in the Y1 subtype receptor for neuropeptide Y could also theoretically cause PP but have not been proven to yet. Interestingly, several genes involved in hypothalamic hamartomas have been found to have increased expression in patients with CPP [18], and great strides in elucidation of the genetic underpinnings of the condition will undoubtedly continue. Table 2 describes the genetic mutations that have been discovered to form the basis of CPP along with their putative physiologic effect on the regulation of the HPG axis.

\section{Diagnosis}

\subsection{Clinical Signs}

Girls with CPP usually present with breast development with or without pubic hair. When present, clinical evidence of both estrogen and androgens is important in differentiating CPP from benign premature thelarche. Boys will present with bilateral testicular enlargement as opposed to boys with peripheral PP in whom the testes are prepubertal or only slightly enlarged. $\mathrm{CPP}$ is also characterized by ongoing pubertal progression as well as growth acceleration and advanced skeletal maturation.

\subsection{Laboratory evaluation:}

A GnRH stimulation test is the gold standard for the diagnosis of CPP. However, synthetic GnRH is no longer available in the United States. Therefore, GnRHas have been used instead. A multitude of different protocols have been suggested, ranging from single sample LH levels to abbreviated or prolonged algorithms involving serial LH testing $(19,20)$. Regardless of which of 
these tests is used, a peak stimulated LH level of $\sim 4-6 \mathrm{mIU} / \mathrm{L}[21]$ or an LH/ FSH ratio $>0.66$ is considered pubertal by many endocrinologists [22, 23]. With the increasing sensitivity of LH assays, a random ultrasensitive LH level is now used in lieu of stimulation testing by many centers. An LH level $>0.2-0.3$ (depending on the assay) is considered consistent with CPP [24,

25]. However, one should keep in mind that basal ultrasensitive LH is often prepubertal in early CPP and may be falsely reassuring [1]. Measurement of sex steroids (basal or stimulated) is not diagnostic alone but can be helpful as supportive data in ambiguous cases, particularly serum testosterone levels. In contrast, random estradiol levels are often unmeasurable even in girls in whom puberty is significantly advanced.

\subsection{Imaging:}

Pelvic ultrasonography has been used in the evaluation of precocious puberty. It is specifically useful in equivocal cases since uterine and ovarian dimensions have a stronger correlation with bone age than with chronological age and are correlated with CPP up to the age of 8 years [26]. As would be expected, girls with CPP have larger uterine and ovarian volumes as compared to girls who are prepubertal and girls with premature thelarche. However, diagnostic thresholds for uterine and ovarian volumes are variable and there is significant overlap between patients with CPP and other benign variants. $[26,27,28]$. Also, the finding of small ovarian follicles on a pelvic ultrasound is normal even in prepubertal girls [29]. Needless to say, ultrasound is technician dependent and difficult to standardize, and its routine use in the evaluation of early puberty in girls varies significantly between different centers.

Once CPP is confirmed with laboratory testing, a brain MRI is considered to rule out the presence of CNS abnormalities. Given the high prevalence of CNS abnormalities in males, it is recommended that all boys with CPP undergo brain imaging $[7,30]$. However, the prevalence of 
CNS abnormalities in girls is much lower, varying between $0 \%$ and $27 \%$ among different studies and decreases with increasing age [31-33]. Because some of these rates include incidental lesions, the actual prevalence of brain tumors and other pathology requiring intervention is even smaller [34]. A meta-analysis based on 15 studies comprising a total of 1853 patients found an overall rate of abnormal MRIs of 9\% which decreased to $7 \%$ when only girls with CPP older than 6 years were included (35). Based on these data and in light of discussions regarding the decreasing age of normal puberty, it is hard to justify routine brain MRI scanning in all girls presenting with puberty before the age of 8 . It has been suggested that girls with CPP should have a brain MRI performed routinely only if they are younger than 6 years of age [2] or have neurological symptoms. However, cranial MRI continues to be performed routinely in many centers in all the girls presenting with breast development before the age of 8 due to the risk of finding an occult intracranial lesion.

\section{Treatment}

\subsection{Goals of Treatment}

The main goal of CPP treatment is to preserve final adult height. However, some patients have a nonprogressive or slowly progressive form of CPP and achieve their genetic potential for height without intervention. Depending on the child's age and the degree of sexual maturation, 6-12 months of observation might be necessary to monitor pubertal progression. If there is minimal change in Tanner staging and if growth velocity remains less than $5-6 \mathrm{~cm} / \mathrm{yr}$, it is considered to be slowly progressing. However, even in patients with clear progression of CPP, the degree of height gain is quite variable after treatment. Therefore, the main dilemma for the endocrinologist is to decide if a patient with CPP needs treatment or not. Multiple parameters need to be considered in order to make this decision including chronological age, the rate of sexual 
maturation, growth velocity and estimated final height together with the degree of bone age advancement.

Age: Many studies have indicated that girls less than 6 years old who have rapid pubertal progression attain the most benefit from the treatment in terms of increasing adult height [2]. While girls between the age of 6-8 years have a variable outcome, girls older than 8 years and those with slowly progressive CPP do not derive any benefit and may even lose height potential as a result of treatment $[3,36]$. Ironically, the vast majority of girls referred for PP are older than age 6 and studies have indicated that many girls being treated with GnRHas for CPP were older than 8 years when therapy was started [37]. There are scarce data for boys because there are far fewer boys than girls with CPP. Regardless, existing data suggest a significant improvement in final height after treatment of CPP in boys [38]. An expert panel concluded that it is reasonable to consider GnRHa treatment in boys with progressive CPP if they present before nine years of age. As in girls, GnRHa therapy results in less height gain for boys with a more advanced bone age at the initiation of therapy.

Tempo of sexual maturation: The tempo of sexual maturation is also an important factor in determining the necessity of treatment. If it is slow, early puberty is less likely to compromise final adult height and treatment is not necessary [39]. In a study of 16 such girls who were followed for 12 years without treatment, all reached a normal adult height [40]. Despite the early onset of breast development in this group, menarche occurred at a normal age. Also, in a study group of 35 boys with slowly progressive puberty who were not treated, adult height was found within the range of their target height [41].

Predicted adult height: There are many different methods that can be used to predict final adult height. One should keep in mind that height prediction methods usually over-predict the adult 
height in children with PP. The most commonly used method was developed by Bayley and Pinneau and provides a table to predict final adult height based upon the child's bone age and absolute height. If the estimated adult height is above $150 \mathrm{~cm}$ in girls and above $160 \mathrm{~cm}$ in boys, treatment is probably not needed to achieve normal adult height. [42].

The other frequently stated goal of treatment in CPP is to relieve potential psychosocial stress caused by early pubertal changes. Parents are usually concerned about early menses, which can be stressful for a young girl as well as her mother. Literature to date has linked precocious puberty to higher rates of depression, suicidal thoughts and behavioral problems than in girls with later-than-average development [43-47]. This prompted some to consider psychological distress as an indication to treat CPP in children. However, in contrast, other studies have failed to find any differences in self-image, self-esteem, or behavioral issues in children with precocious puberty when compared to population norms [48, 49]. Evidence regarding psychological benefit from treatment was deemed inconclusive by the GnRHa Consensus Conference, and more investigation in this area is badly needed [2].

Needless to say, when CPP is caused by a CNS lesion, the underlying pathology should also be treated.

\subsection{Treatment Options}

GnRHas are standard of care for the treatment of CPP. These agents stimulate the pituitary gonadotrophs in a continuous fashion as opposed to the physiologic pulsatile secretion of hypothalamic GnRH. This continuous stimulation leads to suppression of gonadotropins, resulting in decreased sex steroid production. 
GnRHas are derived from native GnRH but contain modifications that result in increased potency and a longer half-life. They were initially approved for the treatment of prostate cancer. After a study showing that treatment with a GnRHa slowed growth velocity and bone age advancement and increased predicted final height in children with CPP [50], the monthly version Lupron Depot was approved by the FDA in 1993. This long-acting GnRHa in the form of monthly intramuscular leuprolide acetate was prescribed almost exclusively for the treatment of CPP in the U.S. for many years. Three-monthly depot preparations, also administered via intramuscular injection, have also been used to treat CPP, particularly in Europe [51]. Several studies as well as a meta-analysis have suggested that the degree of biochemical suppression achieved with 3-monthly dosing is consistently less than that seen with monthly GnRHa administration [51-54]. However, the clinical response to treatment appears to be similar based on limited data. Several other GnRHas have been developed through the years and used for the treatment of CPP including a subcutaneous implant containing histrelin and a six-monthly formulation of triptorelin (Triptodur) that was approved by the FDA for the treatment of CPP in 2017. Similar to other long-acting intramuscular GnRHa preparations, Triptodur has been shown to be effective and safe in children with CPP [55]. Additional 6monthly forms of GnRHas are being investigated with promising initial results.

The initial histrelin implant (Vantus) was first developed for the treatment of metastatic prostate cancer. A similar device (Supprelin) was approved by the FDA in 2007 after it was shown that it suppressed LH and sex steroid concentrations for at least 1 year. The subcutaneous implant allows for sustained release of the potent GnRHa histrelin, and requires a minor outpatient surgical procedure for implantation and removal, which are usually performed under local anesthesia [56]. The device is usually placed in the inner aspect of the upper arm. An initial pilot 
study in 11 girls previously treated with depot triptorelin revealed satisfactory maintenance of LH and FSH suppression following placement of a histrelin implant. Clinical evidence was also promising and included regression of breast development, decreased growth velocity, and attenuation in the rate of skeletal maturation during 15 months of treatment. Less discomfort and lifestyle interference as compared to monthly injections was another plus from this study [57]. This was followed by a phase III study in 36 patients with CPP (20 naïve) that demonstrated profound suppression of the HPG axis within 1 month of placement of the histrelin implant [58]. The extension phase of this study revealed a significant improvement in predicted adult height after up to 6 years of sequential annual histrelin implants [59]. However, an important advancement has been the establishment that a single histrelin implant lasts at least 2 years. This was demonstrated in a study involving 33 children with CPP in whom a single implant was left in place for 2 years [60]. Peak stimulated LH levels at 12 and 24 months were equivalent, and clinical parameters of CPP improved progressively. Use of a single implant for 2 years decreases the cost and numbers of surgical procedures in children treated with this modality.

Other formulations include a daily subcutaneous injection and an intranasal spray with a multiple daily dosing schedule. The biggest concern with these formulations is compliance and subsequent failure of HPG axis suppression. Thus, they are rarely used in the clinical arena. Table 3 illustrates the most commonly used GnRHas along with their respective routes of administration, doses and durations of action.

Several adjunctive treatments above and beyond GnRHas have been proposed for the treatment of CPP including aromatase inhibitors and growth hormone. However, there is no clear evidence at present to support these in routine CPP treatment.

\subsection{Monitoring}


After GnRHa therapy has begun, close monitoring should be performed to ensure that the goals of treatment are being achieved including adequate suppression of the HPG axis, slowing of development of secondary sexual characteristics and diminution in the pace of bone age advancement. Routine monitoring should include evaluation of pubertal development and linear growth velocity along with periodic bone age xrays which are customarily performed annually.

Whether routine monitorization of serum $\mathrm{LH}$ and sex steroid concentrations during GnRHa therapy is necessary is controversial. There are insufficient data to demonstrate that using these measurements to adjust therapy improves adult height outcomes. However, if there is evidence of ongoing pubertal progression once therapy has begun, these measurements may be used to assess whether complete suppression of the HPG axis has been achieved. If this testing suggests incomplete suppression, the GnRHa dose should be increased or the interval between doses should be decreased. It is essential to note, however, that random ultrasensitive LH concentrations often fail to revert to prepubertal values even when the HPG axis is fully suppressed [61]. Thus, a GnRHa stimulation test should be used to confirm lack of suppression when the clinical index of suspicion is high. Baring non-compliance, however, true treatment failure in a child with CPP who is receiving standard doses of a GnRHa is almost unheard of and should prompt an investigation for alternate sources of sex steroid exposure.

Patients and families should be warned that signs of adrenarche such as pubic and axillary hair development will continue to progress and do not reflect treatment inadequacy. In a similar manner, vaginal bleeding might occur within the first weeks following the initial dose of a GnRHa due to estrogen withdrawal. However, if this happens later during the treatment course, inadequate treatment or other possible etiologies must be considered.

\section{Adverse events and long-term concerns}


Overall GnRHas have been shown to be remarkably safe to date. Headaches and hot flushes have been the two most common reported nonspecific side effects. Local skin reactions at the site of depot injections is another one which resolves without intervention. Rarely, sterile abscesses have been reported and a change in treatment modality is necessary. Additionally, the histrelin implant has a potential to become brittle and break upon removal and sometimes ultrasound guided extraction of the fragments is necessary.

There have been several potential long-term concerns raised to date regarding GnRHa therapy. Some authors have claimed that BMI increases during treatment. Despite these anecdotal observations, no negative effect of GnRHa treatment on BMI in girls with CPP has been found in the vast majority of studies [62-64]. Another major concern is reduction in bone mineral density (BMD), which in fact has been shown to be decreased during treatment in girls due to ovarian suppression. However, after treatment is discontinued, BMD is regained, and so women are not significantly different from their peers without a history of CPP [62]. There has been some discussion regarding the incidence of polycystic ovary syndrome (PCOS) in patients treated with GnRHas. Studies have reported variable results with some finding markedly increased rates of PCOS and others finding little or no difference. Thus, there is no consensus at this point on whether CPP or treatment with GnRHas results in an increased risk of PCOS [63]. A final area of concern with GnRHa treatment pertains to reproductive function. Limited long-term follow-up information thus far has indicated normal fertility in treated women with CPP compared with controls. In contrast, untreated women with a history of CPP were found to have higher rates of assisted reproduction and signs of hyperandrogenism suggesting a protective effect of GnRHas in this regard [65]. 
6. Conclusion: CPP is more common in girls and is usually idiopathic. Other rare etiologies include a wide variety of conditions such as CNS lesions, familial cases, and genetic causes which have been recently emerging. Clinical and laboratory evaluation is necessary for diagnosis, as well as imaging studies for selected cases. The decision to treat is complicated and cases should be evaluated carefully from all aspects. GnRHa therapy needs to be considered for a girl presenting with CPP before the age of six with breast and pubic hair development, advanced bone age, and accelerated height velocity. In a girl with somewhat later onset of CPP and/or historically slow progression of pubertal development without a significant increase in height velocity, observation for six to twelve months to understand the pace of the pubertal progression before making a treatment decision is recommended. For boys, all those presenting with CPP before the age of nine years should be treated unless there is evidence of slow pubertal progression. Primary treatment is a GnRHa using one of a variety of available formulations depending on the individual case and local health insurance approval criteria. Bone age, clinical, and if indicated, biochemical indices should be followed during treatment to ensure adequate pubertal suppression. The available evidence regarding both short and long-term outcomes reveals that GnRHas are safe and effective.

\section{Expert Commentary}

Despite great strides in the understanding and management of CPP, important questions remain. Which GnRHa stimulation testing protocol is optimal for diagnosis has not been defined, and whether girls older than age 6 require universal brain MRI scanning remains an active area of controversy. Data regarding the psychological implications of either treated or untreated CPP in girls are decidedly mixed, and further research in this arena should be considered a priority. Recent years have witnessed an exhilarating expansion in identification of monogenic etiologies of CPP 
in both familial and sporadic cases. To date, mutations in four different genes have been shown to form the basis for CPP, two of which are maternally imprinted. As the list of genetic causes of early puberty grows, the percentage of "idiopathic" cases can be anticipated to steadily decrease. The discovery of genetic mutations as the basis for early activation of the HPG axis also affords the promise of exciting novel insights into normal reproductive physiology, further illuminating what has historically been referred to as the "black box" of puberty! An additional area of tremendous progress has been in the development of newer extended release formulations of GnRHas above and beyond traditional depot monthly intramuscular injections. Following the advent of a subcutaneous implant that lasts for at least two years, 3-monthly and 6-monthly intramuscular injectable preparations have entered the clinical setting, resulting in an impressive array of therapeutic options for patients and providers. However, little head-to-head comparative information regarding these disparate long-acting GnRHas is available. Regardless of the preparation being used, whether and what specific strategy for biochemical monitoring during treatment with a GnRHa is needed is another topic of uncertainty. Long-term follow up of patients treated with a GnRHa for CPP has been uniformly reassuring in terms of BMI, bone mineral density and reproductive function in women. However, several spheres of investigation deserve attention. It is intriguing to speculate whether the identification of genetic causes of CPP will in turn lead to the development of new targeted therapies and/or innovative strategies for assessing the degree of HPG axis suppression during treatment. Whether concerns about psychological distress arising from CPP should be used as a rationale for treatment has not been established and demands further study. Although short-term clinical efficacy and safety of the available GnRHa formulations appears to be comparable, whether this will ultimately be confirmed by long-term follow up is unknown. Lastly, a substantial scarcity of knowledge pertaining to boys with CPP 
exists due to the much smaller number of affected individuals. This deficit is present in all facets of clinical care in boys and has implications for making treatment decisions and providing prognosis in terms of expected height gained. Likewise, long-term follow up of boys will be essential in order to interrogate important parameters such as bone health and fertility. It is predicted that future research efforts will be aimed at addressing each of these issues with the ultimate goal of advancing knowledge and improving care of children with CPP.

\section{Key issues:}

- The majority of girls have idiopathic CPP whereas boys are more likely to have a pathological cause.

- The diagnosis of CPP requires a combination of clinical and biochemical factors, as well as imaging studies in selected cases.

- A brain MRI should be obtained in all boys with CPP; MRI in girls is more controversial, with earlier age more clearly necessitating brain MRI.

- Identification of genetic causes of CPP is exciting but is at the beginning of its journey.

- Girls $<6$ years old benefit most from the treatment. Less data exists for boys but treatment should be considered in boys $<9$ years old.

- The gold-standard treatment for CPP is GnRHas which provide sustained high levels of GnRH, resulting in suppression of the HPG axis.

- Multiple formulations of GnRHas are available and they are equally effective in terms of the clinical aspects of CPP. There are some minor differences observed in gonadotropin levels.

- Long-term concerns of children treated with GnRHas for CPP include an increase in BMI, PCOS and decrease in BMD. However, results to date are reassuring. 


\section{References}

1. Nebesio TD, Eugster EA. Current concepts in normal and abnormal puberty. Curr Probl Pediatr Adolesc Health Care. 2007;37(2):50-72.

2. Carel JC, Eugster EA, Rogol A, Ghizzoni L, Palmert MR. Consensus statement on the use of gonadotropin-releasing hormone analogs in children. Pediatrics 2009;123: e75262.

\section{**Proceedings from a multidisciplinary international consensus conference on the use of GnRHas}

3. Fuqua JS. Treatment and outcomes of precocious puberty: an update. J Clin Endocrinol Metab. 2013;98(6): 98-207

4. Tanner JM, Davies PSW. Clinical longitudinal standards for height and height velocity for North American children. J Pediatr. 1985;107(3):317-29.

5. Soriano-Guillen L, Corripio R, Labarta JI, Canete R, Castro-Feijoo L, Espino R, et al. Central precocious puberty in children living in Spain: incidence, prevalence, and influence of adoption and immigration. J Clin Endocrinol Metab. 2010;95(9):4305-13.

6. Lee PA, Neely EK, Fuqua J, Yang D, Larsen LM, Mattia-Gold-berg C, et al. Efficacy of leuprolide acetate 1-month depot for central precocious puberty (CPP): growth outcomes during a prospective, longitudinal study. Int J Pediatr Endocrinol. 2011;2011(1):7.

7. Choi KH, Chung SJ, Kang MJ, Yoon JY, Lee JE, Lee YA, et al. Boys with precocious or early puberty: incidence of pathological brain magnetic resonance imaging findings and factors related to newly developed brain lesions. Ann Pediatr Endocrinol Metab. 2013;18(4):183-90. 
8. de Vries L, Kauschansky A, Shohat M, Phillip M. Familial central precocious puberty suggests autosomal dominant inheritance. J Clin Endocrinol Metab. 2004;89(4):1794800.

9. Rohn R, Rousonelos G. Familial sexual precocity. Am J Dis Child. 1986;140(8):741-2.

10. Teles MG, Bianco SD, Brito VN, Trarbach EB, Kuohung W, Xu S, et al. A GPR54activating mutation in a patient with central precocious puberty. N Engl J Med. 2008; 358(7):709-15.

** First report of a genetic mutation as the cause for CPP

11. Luan X, Yu H, Wei X, Zhou Y, Wang W, Li P, et al. GPR54 polymorphisms in Chinese girls with central precocious puberty. Neuroendocrinology. 2007; 86(2):77-83.

12. Silveira LG, Noel SD, Silveira-Neto AP, Abreu AP, Brito VN, Santos MG, et al. Mutations of the KISS1 gene in disorders of puberty. J Clin Endocrinol Metab. 2010; 95(5):2276-80.

\section{**First description of a KISS1 mutation in a patient with CPP}

13. Abreu AP, Dauber A, Macedo DB, Noel SD, Brito VN, Gill JC, et al. Central precocious puberty caused by mutations in the imprinted gene MKRN3. N Engl J Med. 2013; 368(26):2467-75.

\section{**Discovery of MKRN3 mutations as the basis for familial CPP}

14. Settas N, Dacou-Voutetakis C, Karantza M, Kanaka-Gantenbein C, Chrousos GP, Voutetakis A. Central precocious puberty in a girl and early puberty in her brother caused by a novel mutation in the MKRN3 gene. J Clin Endocrinol Metab. 2014; 99(4): E64751. 
15. Macedo DB, Abreu AP, Reis AC, Montenegro LR, Dauber A, Beneduzzi D, et al. Central precocious puberty that appears to be sporadic caused by paternally inherited mutations in the imprinted gene makorin ring finger 3. J Clin Endocrinol Metab. 2014; 99(6): E1097-103.

16. Dauber A, Cunha-Silva M, Macedo DB, et al. Paternally inherited DLK1 deletion associated with familial central precocious puberty. J Clin Endocrinol Metab 2017;102(5):1557e67.

\section{**Description of DLK1 deletion in CPP}

17. Zhao Y, Chen T, Zhou Y, Li K, Xiao J. An association study between the genetic polymorphisms within GnRHI, LHbeta and FSHbeta genes and central precocious puberty in Chinese girls. Neurosci Lett. 2010; 486(3):188-92.

18. Parent AS, Matagne V, Westphal M, Heger S, Ojeda S, Jung H. Gene expression profiling of hypothalamic hamartomas: a search for genes associated with central precocious puberty. Horm Res. 2008; 69(2):114-23.

19. Yazdani P, Lin Y, Raman V, et al. A single sample GnRHa stimulation test in the diagnosis of precocious puberty. Int J Pediatr Endocrinol 2012;2012(1):23.

20. Houk CP, Kunselman AR, Lee PA. The diagnostic value of a brief GnRH analogue stimulation test in girls with central precocious puberty: a single 30-minute poststimulation LH sample is adequate. J Pediatr Endocrinol Metab 2008;21(12):

21. Lee PA. Laboratory monitoring of children with precocious puberty. Arch Pediatr Adolesc Med 1994;148(4):369e76. 
22. Carretto F, Salinas-Vert I, Granada-Yvern ML, et al. The usefulness of the leuprolide stimulation test as a diagnostic method of idiopathic central precocious puberty in girls. Horm Metab Res 2014;46(13):959e63.

23. Oerter KE, Uriarte MM, Rose SR, et al. Gonadotropin secretory dynamics during puberty in normal girls and boys. J Clin Endocrinol Metab 1990;71(5):1251e8.

24. Houk CP, Kunselman AR, Lee PA. Adequacy of a single unstimulated luteinizing hormone level to diagnose central precocious puberty in girls. Pediatrics 2009;123: e1059-63.

25. Neely EK, Wilson DM, Lee PA, Stene M, Hintz RL. Spontaneous serum gonadotropin concentrations in the evaluation of precocious puberty. J Pediatr 1995; 127:47-52.

26. Eksioglu AS, Yilmaz S, Cetinkaya S, Cinar G, Yildiz YT, Aycan Z. Value of pelvic sonography in the diagnosis of various forms of precocious puberty in girls. J Clin Ultrasound. 2013;41(2):84-93.

27. de Vries L, Horev G, Schwartz M, Phillip M. Ultrasonographic and clinical parameters for early differentiation between precocious puberty and premature thelarche. Eur $\mathrm{J}$ Endocrinol 2006; 154:891.

28. Badouraki M, Christoforidis A, Economou I, et al. Evaluation of pelvic ultrasonography in the diagnosis and differentiation of various forms of sexual precocity in girls. Ultrasound Obstet Gynecol 2008; 32:819.

29. Pienkowski C, Cartault A, Carfagna L, Ernoult P, Vial J, Lemasson F, et al. Ovarian cysts in prepubertal girls. Endocr Dev. 2012; 22:101-11. 
30. DeSanctis V, Corrias A, Rizzo V, Bertelloni S, Urso L, et al. Etiology of central precocious puberty in males: the results of the Italian Study Group for Physiopathology of Puberty. J Pediatr Endocrinol Metab 2000; 13:687-93.

31. Atta I, Laghari TM, Khan YN, Lone SW, Ibrahim M, et al. Precocious puberty in children. J Coll Physicians Surg Pak 2015; 25:124-8.

32. Bridges NA, Christopher JA, Hindmarsh PC, Brook CG. Sexual precocity: sex incidence and aetiology. Arch Dis Child 1994; 70:116-8.

33. Chalumeau M, Chemaitilly W, Trivin C, Adan L, Breart G, et al. Central precocious puberty in girls: an evidence-based diagnosis tree to predict central nervous system abnormalities. Pediatrics 2002; 109:61-7.

34. Pedicelli S, Alessio P, Scirè G, Cappa M, Cianfarani S. Routine screening by brain magnetic resonance imaging is not indicated in every girl with onset of puberty between the ages of 6 and 8 years. J Clin Endocrinol Metab. 2014 Dec;99(12):4455-61.

35. Cantas-Orsdemir S, Garb JL, Allen HF. Prevalence of cranial MRI findings in girls with central precocious puberty: a systematic review and meta-analysis. J Pediatr Endocrinol Metab. 2018 Jul 26;31(7):701-710.

**Meta-analysis of the incidence of intracranial pathology found on MRI in girls with CPP

36. Klein KO, Barnes KM, Jones JV, et al. Increased final height in precocious puberty after long-term treatment with LHRH agonists: the National Institutes of Health experience. J Clin Endocrinol Metab 2001;86(10):4711e6.

37. Watson SE, Greene A, Lewis K, Eugster EA. Bird's eye view of GnRH analog use in a pediatric endocrinology referral center. Endocr Pract. 2015 Jun;21(6):586-9. 
38. Mul D, Bertelloni S, Carel JC, Saggese G, Chaussain JL, Oostdijk W. Effect of gonadotropin releasing hormone agonist treatment in boys with central precocious puberty: final height results. Horm Res. 2002; 58(1):1-7.

39. Kaplowitz P, Bloch C, Section on Endocrinology, American Academy of Pediatrics. Evaluation and Referral of Children with Signs of Early Puberty. Pediatrics 2016; 137.

40. Palmert MR, Malin HV, Boepple PA. Unsustained or slowly progressive puberty in young girls: initial presentation and long-term follow-up of 20 untreated patients. J Clin Endocrinol Metab 1999; 84:415.

41. Lazar L, Pertzelan A, Weintrob N, et al. Sexual precocity in boys: accelerated versus slowly progressive puberty gonadotropin-suppressive therapy and final height. J Clin Endocrinol Metab 2001; 86:4127.

42. Bar A, Linder B, Sobel EH, et al. Bayley-Pinneau method of height prediction in girls with central precocious puberty: correlation with adult height. J Pediatr 1995; 126:955.

43. Nacinovich R, Buzi F, Oggiano S, Rossi S, Apada S, Broggi F, Pilotta A, Neri F, Bomba M. Body experiences and psychopathology in idiopathic central precocious and early puberty. Minerva Pediatr. 2016; 68:11-18.

44. Sonis WA, Comite F, Blue J, Pescovitz OH, Rahn CW, Hench KD, Cutler GB, Jr, Loriaux DL, Klein RP. Behavior problems and social competence in girls with true precocious puberty. J Pediatr. 1985; 106:156-160.

45. Jackson PL, Ott MJ. Percieved self-esteem among girls diagnosed with precocious puberty. J Pediatr Nurs. 1990; 5:190-203.

46. Blumenthal H, Leen-Feldner EW, Babson KA, Gahr JL, Trainor CD, Frala JL. Elevated social anxiety among early maturing girls. Dev Psychol. 2011; 47:1133-1140. 
47. Kaltiala-Heino R, Marttunen M, Rantanen P, et al. Early puberty is associated with mental health problems in middle adolescence. Soc Sci Med 2003;57(6):1055e64.

48. Ehrhardt AA, Meyer-Balhlburg HF, Bell JJ, Cohen SF, Healey JM, Stiel R, Feldman JF, Morishima A, New MI. Idiopathic precocious puberty in girls: psychiatric follow-up in adolescence. J Am Acad Child Adolesc Psychiatry. 1984; 23:23-33.

49. Sonis WA, Comite F, Pescovitz OH, Hench K, Rahn CW, Cutler GB, Jr, Loriaux DL, Klein RP. Biobehavioral aspects of precocious puberty. J Am Acad Child Psychiatry. 1986; 25:674-679.

50. Comite F, Cassorla F, Barnes KM, Hench KD, Dwyer A, Skerda MC, et al. Luteinizing hormone releasing hormone analogue therapy for central precocious puberty. Long-term effect on somatic growth, bone maturation, and predicted height. JAMA. 1986 May;255(19):2613-6.

51. Carel JC, Blumberg J, Seymour C, et al. Three-month sustained-release triptorelin (11.25 $\mathrm{mg}$ ) in the treatment of central precocious puberty. Eur J Endocrinol 2006;154(1):119e24.

52. Lee PA, Klein K, Mauras N, et al. Efficacy and safety of leuprolide acetate 3-month depot 11.25 milligrams or 30 milligrams for the treatment of central precocious puberty. J Clin Endocrinol Metab 2012;97(5):1572e80.

53. Fuld K, Chi C, Neely EK. A randomized trial of 1- and 3-month depot leuprolide doses in the treatment of central precocious puberty. J Pediatr 2011;159(6).

54. Duarnd A, Tauber M, Patel B, et al. Meta-analysis of paediatric patients with central precocious puberty treated with intramuscular triptorelin $11.25 \mathrm{mg} 3$-month prolongedrelease formulation. Horm Res Paediatr 2017;87(4):224e32. 


\section{**Meta-analysis of 3-monthly triptorelin}

55. Klein K, Yang J, Aisenberg J, et al. Efficacy and safety of triptorelin 6-month formulation in patients with central precocious puberty. J Pediatr Endocrinol Metab 2016;29(11):1241e8.

\section{6. **First report of a 6-monthly depot GnRHa}

57. Lewis KA, Eugster EA. Experience with the once-yearly histrelin (GnRHa) subcutaneous implant in the treatment of central precocious puberty. Drug Des Dev Ther 2009; 3:1e5.

58. Hirsch HJ, Gillis D, Strich D, Chertin B, Farkas A, Lindenberg T, et al. The histrelin implant: a novel treatment for central precocious puberty. Pediatrics. 2005;116(6): e798802.

59. **First report of the use of the histrelin implant to treat CPP

60. Silverman, LA., Neely, EK., Kletter, GB., Lewis, K., Chitra, S., Terleckyj, O., Eugster, EA. J Clin Endocrinol Metab. Long-term continuous suppression with once-yearly histrelin subcutaneous implants for the treatment of central precocious puberty: a final report of a phase 3 multicenter trial. Epub 2015 Mar 24

61. Eugster EA, Clarke W, Kletter GB, Lee PA, Neely EK, Reiter EO, et al. Efficacy and safety of histrelin subdermal implant in children with central precocious puberty: a multicenter trial. J Clin Endocrinol Metab. 2007; 92(5):1697-704.

62. Lewis KA, Goldyn AK, West KW, Eugster EA. A single histrelin implant is effective for 2 years for treatment of central precocious puberty. J Pediatr. 2013; 163(4):1214-6.

63. Lewis KA, Eugster EA. Random luteinizing hormone often remains pubertal in children treated with the histrelin implant for central precocious puberty. J Pediatr. 2013 Mar;162(3):562-5. 
64. Pasquino AM, Pucarelli I, Accardo F, Demiraj V, Segni M, Di Nardo R. Long-term observation of 87 girls with idiopathic central precocious puberty treated with gonadotropin-releasing hormone analogs: impact on adult height, body mass index, bone mineral content, and reproductive function. J Clin Endocrinol Metab. 2008; 93(1):190-5.

65. Magiakou MA, Manousaki D, Papadaki M, Hadjidakis D, Le-vidou G, Vakaki M, et al. The efficacy and safety of gonadotropin-releasing hormone analog treatment in childhood and adolescence: a single center, long-term follow-up study. J Clin Endocrinol Metab. 2010; 95(1): 109-17.

66. Poomthavorn P, Suphasit R, Mahachoklertwattana P. Adult height, body mass index and time of menarche of girls with id-iopathic central precocious puberty after gonadotropinreleasing hormone analogue treatment. Gynecol Endocrinol. 2011; 27(8):524-8.

67. Lazar L, Meyerovitch J, de Vries L, Phillip M, Lebenthal Y. Treated and untreated women with idiopathic precocious puberty: long-term follow-up and reproductive outcome between the third and fifth decades. Clin Endocrinol (Oxf). 2014 Apr;80(4):5706.

\section{** Long-term follow up of reproductive function in women treated with a GnRHa for CPP}

